\title{
An investigation of attitudes, beliefs and behaviour of leprosy patients, family members and PHC workers towards multidrug therapy in Yangzhou and Dongtai Districts of China
}

\author{
CHEN XIANG-SHENG, * YE GAN-YUN,* \\ JIANG CHENG, ${ }^{*}$ LI WEN-ZHONG, ${ }^{*}$ BIAN JINGUO, $\dagger$ \\ WANG HOUZHENG $\ddagger \&$ CHEN WENHUA $\dagger$ \\ * Department for Leprosy Research, Institute of Dermatology, CAMS \\ \& PUMC, National Center for STD and Leprosy Control, 12 Jiang- \\ wangmiao Street, Nanjing 210042; †Yangzhou Institute of Dermatol- \\ ogy, Yangzhou 225300; $\ddagger$ Dongtai Institute of Dermatology, Dongtai \\ 224200, China
}

Accepted for publication 24 September 1996

\begin{abstract}
Summary To improve the operational efficiency of multidrug therapy (MDT) implementation in rural areas, an investigation into the attitudes, beliefs and behaviour of leprosy patients and their family members as well as primary health care (PHC) workers towards MDT was carried out in Yangzhou and Dongtai Districts of China. A sample of 370 leprosy patients, 594 family members and 730 PHC workers was interviewed or investigated individually using questionnaires. The results showed that: 1 , the presently used MDT is acceptable to a wide range of patients although a small number of patients have various problems in their treatment; 2 , the patients' habit in daily drug administration, their awareness of the risk of default and confidence in MDT have a positive influence in increasing drug compliance; and 3, the supervision and encouragement of family members to patients' treatment which is associated with their knowledge on MDT is also beneficial to patients' drug compliance. However, only half of the PHC workers had a basic knowledge of MDT and a desire to participate in MDT implementation, a finding which clearly calls for urgent attention and improvement. In order to ensure the effective implementation of MDT, there is a need to educate leprosy patients and their family members as well as PHC workers to establish the patients' correct awareness of MDT, obtain the family support and motivate the PHC workers.
\end{abstract}

\section{Introduction}

The introduction of multidrug therapy (MDT) recommended by WHO has been a major advance in the treatment of leprosy because of its relatively short treatment course and a low rate of relapse. ${ }^{1-4}$ Since MDT was implemented in Jiangsu Province in 1984, almost all the 
newly-detected leprosy cases have been treated with these regimens on a domiciliary basis. In order to ensure the effectiveness of presently used MDT, it is important to have an insight into the social aspects associated with its operational implementation. In this paper, the results of a sociomedical investigation on MDT implementation among the leprosy patients and their family members, and primary health care $(\mathrm{PHC})$ workers are reported.

\section{Materials and methods}

Yangzhou and Dongtai Districts are situated in the North of Jiangsu Province of China with a total of 21,534 accumulated cases of leprosy since 1949 and 1551 cases treated with 'loose' drugs of WHO-MDT (MB-MDT 1229 and PB-MDT 322) since 1984 were selected for the investigation. In these areas, the WHO regimens were usually delivered to patients' homes at monthly intervals by the designated leprosy field workers of the County Station for Skin Disease Control with monthly supervised intake of rifampicin $600 \mathrm{mg}$, clofazimine $300 \mathrm{mg}$, together with daily, unsupervised clofazimine $50 \mathrm{mg}$ and dapsone $100 \mathrm{mg}$ for MB patients; monthly supervised rifampicin $600 \mathrm{mg}$ and daily, unsupervised dapsone $100 \mathrm{mg}$ for PB patients. Some patients, however, collected their drugs and were supervised at skin clinics, and a small number of patients liked to be treated in secret and/or without supervision in order to avoid the social stigma from community to their families. A sample of 370 leprosy patients and 596 of their family members were selected randomly from these areas and interviewed individually using the questionnaires. The interview was conducted by the authors with the assistance of the leprosy field workers who were experienced in dealing with leprosy patients and their family members. Before the interview, the aims and purpose of the investigation were clearly explained to the interviewees. Also, a sample of 730 PHC workers, including 137 part-time leprosy workers (PLWs), 61 paramedical workers (PMWs), 76 township health workers (THWs), 343 village health workers (VHWs) and 113 managerial health workers (MHWs), were investigated using the questionnaires in the same areas.

Drug compliance was defined as taking more than $90 \%$ of the prescribed medications estimated through the intensive interview.

All data from the questionnaires were put into the computer to establish a database, and analysed using the computer software of EpiInf 5.0.

\section{Results}

There were 370 (279 male and 91 female) leprosy patients with an average age of $49 \cdot 6 \pm 12 \cdot 9$ years, including 257 cases $(69.5 \%)$ on MB-MDT and $113(30.5 \%)$ on PB-MDT, and 594 members with an average age of $43.0 \pm 6 \cdot 4$ years from these patients' families who responded to the questionnaires.

Leprosy patients were questioned about their treatment behaviour and beliefs in an attempt to determine whether their behaviour and beliefs were associated with their drug compliance (Table 1). The daily drug administration at a fixed time, patients' awareness of the risk of drug default and their confidence in MDT had a statistically significant affect in increasing patients' drug compliance. However, whether treated in the usual way with monthly attendance and supervision, or secretly, the drug compliance rate was the same. When questioned on the biggest problem in their treatment, $24.3 \%$ of patients had problems 
Table 1. Relationship between patients' treatment modes/beliefs to MDT and their drug compliance

\begin{tabular}{|c|c|c|c|c|}
\hline \multirow[b]{2}{*}{ Patients treatment modes/beliefs to MDT } & \multicolumn{2}{|c|}{ Drug compliance } & \multirow[b]{2}{*}{ Total } & \multirow[b]{2}{*}{$\chi^{2}$-test } \\
\hline & Yes & No & & \\
\hline \multicolumn{5}{|l|}{ Being supervised } \\
\hline Yes & $256(74 \cdot 9)$ & $86(25 \cdot 1)$ & $342(100 \cdot 0)$ & $0 \cdot 19$ \\
\hline No & $22(78 \cdot 6)$ & $6(21 \cdot 4)$ & $28(100 \cdot 0)$ & NS* \\
\hline \multicolumn{5}{|l|}{ Drug delivery } \\
\hline Home delivery & $136(74 \cdot 7)$ & $46(26 \cdot 3)$ & $182(100 \cdot 0)$ & $3 \cdot 24$ \\
\hline Clinic collection & $84(71 \cdot 2)$ & $34(28 \cdot 8)$ & $118(100 \cdot 0)$ & NS \\
\hline Hospitalization & $58(82.9)$ & $12(17 \cdot 1)$ & $70(100 \cdot 0)$ & \\
\hline \multicolumn{5}{|l|}{ Daily administration } \\
\hline Fixed time & $253(78 \cdot 1)$ & $71(21 \cdot 9)$ & $324(100 \cdot 0)$ & $12 \cdot 15$ \\
\hline Indefinite time & $25(54 \cdot 3)$ & $21(45 \cdot 7)$ & $46(100 \cdot 0)$ & HS \\
\hline \multicolumn{5}{|l|}{ Secret treatment } \\
\hline Yes & $105(77 \cdot 2)$ & $31(22 \cdot 8)$ & $136(100 \cdot 0)$ & $0 \cdot 49$ \\
\hline No & $173(73.9)$ & $61(26 \cdot 1)$ & $234(100 \cdot 0)$ & NS \\
\hline \multicolumn{5}{|l|}{ Risk of drug default } \\
\hline Awareness & $246(76.9)$ & $74(23 \cdot 1)$ & $320(100 \cdot 0)$ & $3 \cdot 84$ \\
\hline Unawareness & $32(64 \cdot 0)$ & $18(36 \cdot 0)$ & $50(100 \cdot 0)$ & SS \\
\hline \multicolumn{5}{|l|}{ Confidence in MDT } \\
\hline Yes & $221(78 \cdot 6)$ & $60(21 \cdot 4)$ & $281(100 \cdot 0)$ & $7 \cdot 71$ \\
\hline No & $57(64 \cdot 0)$ & $32(36 \cdot 0)$ & $89(100 \cdot 0)$ & HS \\
\hline Total & $278(75 \cdot 1)$ & $92(24 \cdot 9)$ & $370(100 \cdot 0)$ & - \\
\hline
\end{tabular}

Numbers in parentheses are percentages. ${ }^{*}$ NS: $p>0 \cdot 05$; SS: $p<0 \cdot 05$; HS: $p<0.01$.

and more MB-MDT patients $(30 \cdot 4 \%)$ had problems than PB-MDT patients $(10 \cdot 7 \%)$ $\left(\chi^{2}=16 \cdot 6, p<0 \cdot 001\right)$. Of 78 MB-MDT patients with problems, for about $50 \%$ had the biggest problem was skin discoloration due to clofazimine and for $25 \%$ the biggest problem was the length of treatment. However, the vast majority of both MB-MDT (99.6\%) and PB-MDT $(98.2 \%)$ patients could accept or tolerate the present regimen-duration of MDT (Table 2). Among the noncompliant patients, the common reasons contributing to the patients' noncompliance in these areas were their farming activities (70\%) and frequent movement from place to place $(10 \%)$.

As shown in Tables 3 and 4, only $20 \cdot 2 \%$ of family members had a basic knowledge of MDT. Of those who had the knowledge, $60 \cdot 8 \%$ supervised and encouraged their family patient's treatment at home, whereas $42.4 \%$ who did not have any knowledge of MDT did so $\left(\chi^{2}=13 \cdot 1, p<0 \cdot 001\right)$. On the other hand, the supervision and encouragement of family members, mainly from their parents and spouses, significantly increased drug compliance.

Out of 730 PHC workers, $41.0 \%$ had a basic knowledge of MDT, $41.0 \%$ had an involvement in MDT implementation before and $52.9 \%$ had a desire to participate in it in future. As shown in Table 5, VHWs were a group in which fewer workers had knowledge about MDT but more had a desire to participate in MDT implementation in future, as compared with the others except PLWs.

\section{Discussion}

It is clear that the introduction of multidrug therapy (MDT) recommended by WHO has 
Table 2. Attitudes towards the biggest problem in MDT treatment and the acceptability of the present MDT course

\begin{tabular}{|c|c|c|c|}
\hline \multirow[b]{2}{*}{ Patients' attitudes } & \multicolumn{2}{|c|}{ MDT Regimens } & \multirow[b]{2}{*}{ Total } \\
\hline & MDT-MB & MDT-PB & \\
\hline \multicolumn{4}{|l|}{ The biggest problem } \\
\hline No problem & $179(69 \cdot 6)^{*}$ & $101(89 \cdot 4)$ & $280(75 \cdot 7)$ \\
\hline Long MDT course & $21(8 \cdot 2)$ & $4(3 \cdot 5)$ & $25(6 \cdot 8)$ \\
\hline Discoloration & $38(14 \cdot 8)$ & $0(0 \cdot 0)$ & $38(10 \cdot 3)$ \\
\hline Other side-effects & $12(4 \cdot 7)$ & $2(1 \cdot 8)$ & $14(3 \cdot 7)$ \\
\hline \multirow[t]{2}{*}{ Others } & $7(2 \cdot 7)$ & $6(5 \cdot 3)$ & $13(3 \cdot 5)$ \\
\hline & \multicolumn{2}{|c|}{$\chi^{2}=26.5, p<0 \cdot 01$} & \\
\hline \multicolumn{4}{|l|}{ Present MDT course } \\
\hline Acceptable & $256(99 \cdot 6)$ & $111(98 \cdot 2)$ & $367(99 \cdot 2)$ \\
\hline \multirow[t]{2}{*}{ Unacceptable } & $1(0 \cdot 4)$ & $2(1 \cdot 8)$ & $3(0 \cdot 8)$ \\
\hline & \multicolumn{2}{|c|}{$\chi^{2}=1.9, p>0.05$} & \\
\hline Total & $257(100 \cdot 0)$ & $113(100 \cdot 0)$ & $370(100 \cdot 0)$ \\
\hline
\end{tabular}

* Numbers in parentheses are percentages.

offered an important opportunity to attain the global elimination of leprosy as a public health problem by the year 2000. However, for the effective implementation of MDT, it is not only the 'therapeutic factors', but also the 'patient factors' and 'service factors' which require consideration. ${ }^{5}$ Moreover, the patient factors are often given priority for consideration. ${ }^{6}$ This

Table 3. Family members' knowledge of MDT, different family relation and their behaviour to patients' treatment

Supervising/encouraging patients' treatment

\begin{tabular}{|c|c|c|c|}
\hline & Yes & No & Total \\
\hline \multicolumn{4}{|c|}{ MDT knowledge } \\
\hline Yes & $73(60 \cdot 8)^{*}$ & $47(39 \cdot 2)$ & $120(100 \cdot 0)$ \\
\hline \multirow[t]{2}{*}{ No } & $201(42 \cdot 4)$ & $273(57 \cdot 6)$ & $474(100 \cdot 0)$ \\
\hline & \multicolumn{2}{|c|}{$\chi^{2}=13 \cdot 1, p<0.001$} & \\
\hline \multicolumn{4}{|c|}{ Family relation } \\
\hline Parents & $48(60 \cdot 0)$ & $32(40 \cdot 0)$ & $80(100 \cdot 0)$ \\
\hline Spouses & $130(60 \cdot 5)$ & $85(39 \cdot 5)$ & $215(100 \cdot 0)$ \\
\hline Children & $58(34 \cdot 3)$ & $111(65 \cdot 7)$ & $169(100 \cdot 0)$ \\
\hline \multirow[t]{2}{*}{ Siblings } & $38(29 \cdot 2)$ & $92(70 \cdot 8)$ & $130(100 \cdot 0)$ \\
\hline & \multicolumn{2}{|c|}{$\chi^{2}=48.4, p<0.001$} & \\
\hline Total & $274(46 \cdot 1)$ & $320(53 \cdot 9)$ & $594(100 \cdot 0)$ \\
\hline
\end{tabular}

* Numbers in parentheses are percentages. 
Table 4. Family members' behaviour to patients' treatment and patients' drug compliance

\begin{tabular}{lccc}
\hline \multicolumn{2}{c}{ Drug compliance } & \\
\cline { 2 - 3 } & \multicolumn{2}{c}{ Yes } & Total \\
\hline \multicolumn{2}{c}{ Supervising/encouraging patients' treatment } & \\
Yes & $239(87 \cdot 2)^{*}$ & $35(12 \cdot 8)$ & $274(100 \cdot 0)$ \\
No & $245(76 \cdot 6)$ & $75(23 \cdot 4)$ & $320(100 \cdot 0)$ \\
\cline { 2 - 3 } & \multicolumn{2}{c}{$\chi^{2}=11 \cdot 6, \quad p<0 \cdot 001$} & \\
Total & $484(81 \cdot 5)$ & $110(18 \cdot 5)$ & $594(100 \cdot 0)$ \\
\hline
\end{tabular}

* Numbers in parentheses are percentages.

investigation is designed to evaluate the attitudes, beliefs and behaviour of patients and their family members as well as medical workers towards MDT.

Although some patients collected their drugs and were supervised at skin clinics, and even a small number of patients were treated secretly and/or without supervision in order to avoid the social stigma from community to their families, their drug compliance fortunately was not decreased. The patients' drug administration at a fixed time, awareness of the risk of drug default and confidence in MDT had a significant affect on enhancing their drug compliance (Table 1).

As confirmed by this investigation, a very high proportion of $\mathrm{MB}$ patients agreed to take MDT in spite of the main problem of skin discoloration due to clofazimine (a constituent of MDT), and the MDT regimen-duration was acceptable to a vast majority of patients, since the benefits of MDT have been very well appreciated. ${ }^{2}$ However, patients' behaviour in response to treatment is not only determined by their subjective desire, but influenced by some objective social and environmental factors such as agricultural activities and population migration. ${ }^{6}$ As found in this study, $80 \%$ of the noncompliant patients believed that their noncompliance was due mainly to their farming activities and/or frequent movement from place to place. It is our experience that some patients in rural areas believe that their

Table 5. Attitudes, beliefs and behaviour of PHC workers towards MDT

\begin{tabular}{lcccr}
\hline Personnel & Number & $\begin{array}{c}\text { Knowledge } \\
\text { on MDT }\end{array}$ & $\begin{array}{c}\text { Involvement } \\
\text { in MDT }\end{array}$ & $\begin{array}{r}\text { Desire to } \\
\text { participate }\end{array}$ \\
\hline PLWs & 137 & $67(48 \cdot 9) *$ & $81(59 \cdot 1)$ & $81(59 \cdot 1)$ \\
PMWs & 61 & $27(44 \cdot 3)$ & $24(39 \cdot 3)$ & $28(45 \cdot 9)$ \\
THWs & 76 & $34(44 \cdot 7)$ & $13(17 \cdot 1)$ & $26(34 \cdot 2)$ \\
VHWs & 343 & $121(35 \cdot 3)$ & $150(43 \cdot 7)$ & $199(58 \cdot 0)$ \\
MHWs & 113 & $50(44 \cdot 2)$ & $31(27 \cdot 4)$ & $52(46 \cdot 0)$ \\
$\chi^{2}$ test & - & $p>0 \cdot 05$ & $p<0 \cdot 01$ & $p<0 \cdot 01$ \\
Total & 730 & $299(41 \cdot 0)$ & $299(41 \cdot 0)$ & $386(52 \cdot 9)$ \\
\hline
\end{tabular}

* Numbers in parentheses are percentages. 
agricultural activities, especially the farming activities is more important than their regular MDT treatment.

Family has played an important role in leprosy control. Family members' knowledge about MDT and their relation to the patient within family determine their behaviour towards patient's treatment. Family members who have knowledge of MDT and a closer relation to patients tended to give more supervision and encourage the patients' treatment, which could significantly increase the patients' drug compliance.

The concept of the integration of leprosy case into general health care has been proven worthy to be recommended, based on the consideration that it will lead to much more efficient use of staff, transportation and financial resources. ${ }^{8,9}$ At present, the leprosy control project in the investigated areas is mainly run as a semivertical control programme and is in a process of transition towards integration into primary health care. However, from the results of this investigation it must be pointed out that amongst the 730 PHC workers only $41.0 \%$ had a basic knowledge about MDT, $41.0 \%$ had been involved in MDT work before and only $52.9 \%$ had a desire to participate in MDT implementation in future, which meant that in terms of PHC workers the improvement of their knowledge and the motivation of their involvement in MDT should be a prerequisite for the integration of leprosy care. ${ }^{3}$ Interestingly, amongst the PHC workers, VHWs were a group which had less knowledge about MDT but more desired to participate in MDT implementation, suggesting that VHWs may be the easier access to PHC workers for the integration.

\section{Conclusion}

The conclusion drawn from this investigation is that in order to ensure the effective implementation of MDT and its successful integration into primary health care, the greater emphasis must be given to health education. In addition, the supervision of MDT in farming activities, and the management of MDT must be strengthened. The revelation in this study that only half the PHC workers interviewed had a basic knowledge of MDT and a desire to participate in MDT implementation clearly calls for urgent attention.

\section{Acknowledgments}

This investigation was generously supported by the Ciba-Geigy Leprosy Fund. We wish to thank our leprosy field workers, PHC workers, leprosy patients and their family members who contributed to this investigation. We also thank Mrs Jin Yi for her secretarial help in data and manuscript preparation.

\section{References}

1 WHO. Chemotherapy of leprosy for control programmes. Report of a WHO Study Group. Technical Report Series 675. World Health Organization, Geneva, 1982.

2 Noordeen SK. Eliminating leprosy as a public health problem; why the optimism is justified. Int J Lepr, 1995; 63: 559.

${ }^{3}$ Feenstra P. Needs and prospects for epidemiological tools in leprosy control. Lepr Rev, 1992; 63 (suppl): 3s-10s.

${ }^{4}$ WHO. Risk of relapse in leprosy. WHO/CTD/LEP/94.1 The Leprosy Unit, Division of Control of Tropical Diseases, WHO, Geneva, Switzerland. 
${ }^{5}$ Premkumar R and Dave SL. Impact of multidrug therapy on health personnel in their level of job satisfaction. Indian J Lepr, 1993; 65: 429-438.

${ }^{6}$ Gilbody JS. Impact of MDT on the treatment and control of leprosy. Int J Lepr, 1991; 59: 458-478.

${ }^{7}$ Hertroijs AR. A study of some factors affecting the attendance of patients in a leprosy control scheme. Int J Lepr, 1974; 42: 419-438.

${ }^{8}$ Haydar, AH. Leprosy control in a primary health care programme in the Sudan. Lepr Rev, 1982; 53: 175.

9 Nkinda SJ. Leprosy and primary health care: Tanzania. Lepr Rev, 1982; 53: 165-173. 